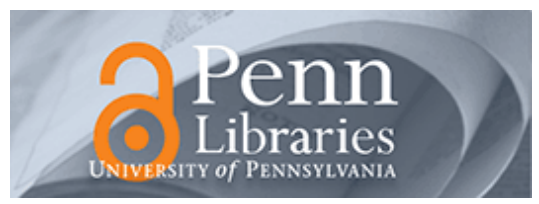

University of Pennsylvania

ScholarlyCommons

Operations, Information and Decisions Papers

Wharton Faculty Research

$12-2012$

\title{
Protective Measures, Personal Experience, and the Affective Psychology of Time
}

\author{
Ellen Peters
}

Howard Kunreuther

University of Pennsylvania

Namika Sagara

Paul Slovic

Dan R. Schley

Follow this and additional works at: https://repository.upenn.edu/oid_papers

Part of the Other Education Commons, Other Psychology Commons, and the Theory, Knowledge and Science Commons

\section{Recommended Citation}

Peters, E., Kunreuther, H., Sagara, N., Slovic, P., \& Schley, D. R. (2012). Protective Measures, Personal Experience, and the Affective Psychology of Time. Risk Analysis, 32 (12), 2084-2097. http://dx.doi.org/ 10.1111/j.1539-6924.2012.01810.x

At the time of publication, author Howard Kunreuther was affiliated with the Columbia University. Currently (June 2006), he is a faculty member in the Marketing Department of the Wharton School at the University of Pennsylvania.

This paper is posted at ScholarlyCommons. https://repository.upenn.edu/oid_papers/56

For more information, please contact repository@pobox.upenn.edu. 


\title{
Protective Measures, Personal Experience, and the Affective Psychology of Time
}

\begin{abstract}
We examined the role of time and affect in intentions to purchase a risk-protective measure (Studies 1 and 2) and explored participant abilities to factor time into the likelihood judgments that presumably underlie such intentions (Study 3). Participants worried more about losing their possessions and were more likely to purchase a protective measure given a longer term lease than a short-term lease, but only if their belongings were described in affect-poor terms. If described instead as being particularly special and affect-rich, participants neglected time and were about equally likely to purchase a risk-protective measure for shorter and longer term leases. However, and consistent with prior literature, the cognitive mechanism underlying this time-neglect-with-affect-richness effect seemed to be the greater use of the affect heuristic in the shorter term than the longer term. Study 2 results demonstrated that prior experience with having been burglarized amplified the interactive effect of time and affect. Greater deliberation did not attenuate this effect as hypothesized whether deliberation was measured through numeracy or manipulated through instructions. The results of Study 3 indicated that few participants are able to calculate correctly the risk numbers necessary to take time into account. Two possible solutions to encourage more purchases of protective measures in the long term are discussed.
\end{abstract}

\section{Keywords}

Affect, personal experience, risk perception

Disciplines

Other Education | Other Psychology | Theory, Knowledge and Science

\section{Comments}

At the time of publication, author Howard Kunreuther was affiliated with the Columbia University. Currently (June 2006), he is a faculty member in the Marketing Department of the Wharton School at the University of Pennsylvania. 


\section{Protective measures, personal experience, and the affective psychology of time}

\section{Ellen Peters}

Ohio State University
Howard Kunreuther

The Wharton School University of Pennsylvania

\section{Namika Sagara}

Duke University
Paul Slovic

University of Oregon,

Decision Research
Dan R. Schley

Ohio State University

February 2012

Working Paper \# 2012-03

Risk Management and Decision Processes Center

The Wharton School, University of Pennsylvania

3730 Walnut Street, Jon Huntsman Hall, Suite 500

Philadelphia, PA, 19104

USA

Phone: 215-898-5688

Fax: 215-573-2130

http://opim.wharton.upenn.edu/risk/ 


\section{THE WHARTON RISK MANAGEMENT AND DECISION PROCESSES CENTER}

Established in 1984, the Wharton Risk Management and Decision Processes Center develops and promotes effective corporate and public policies for low-probability events with potentially catastrophic consequences through the integration of risk assessment, and risk perception with risk management strategies. Natural disasters, technological hazards, and national and international security issues (e.g., terrorism risk insurance markets, protection of critical infrastructure, global security) are among the extreme events that are the focus of the Center's research.

The Risk Center's neutrality allows it to undertake large-scale projects in conjunction with other researchers and organizations in the public and private sectors. Building on the disciplines of economics, decision sciences, finance, insurance, marketing and psychology, the Center supports and undertakes field and experimental studies of risk and uncertainty to better understand how individuals and organizations make choices under conditions of risk and uncertainty. Risk Center research also investigates the effectiveness of strategies such as risk communication, information sharing, incentive systems, insurance, regulation and public-private collaborations at a national and international scale. From these findings, the Wharton Risk Center's research team - over 50 faculty, fellows and doctoral students - is able to design new approaches to enable individuals and organizations to make better decisions regarding risk under various regulatory and market conditions.

The Center is also concerned with training leading decision makers. It actively engages multiple viewpoints, including top-level representatives from industry, government, international organizations, interest groups and academics through its research and policy publications, and through sponsored seminars, roundtables and forums.

More information is available at http://opim.wharton.upenn.edu/risk. 
Protective measures, personal experience, and the affective psychology of time

Peters, E.,

Kunreuther, H.,

Sagara, N.,

Slovic, P., \&

Schley, D.R. 


\begin{abstract}
We examined the role of time and affect in intentions to purchase a risk-protective measure (Studies 1 and 2) and explored participant abilities to factor time into the likelihood judgments that presumably underlie such intentions (Study 3). Participants worried more about losing their possessions and were more likely to purchase a protective measure given a longer term lease than a short-term lease, but only if their belongings were described in affect-poor terms. If described instead as being particularly special and affect-rich, participants neglected time and were about equally likely to purchase a risk-protective measure for shorter and longer term leases. However and consistent with prior literature, the cognitive mechanism underlying this time-neglect-with-affect-richness effect appeared to be the greater use of the Affect Heuristic in the shorter term than the longer term. Study 2 results demonstrated that prior experience with having been burglarized amplified the interactive effect of time and affect. Greater deliberation did not attenuate this effect as hypothesized whether deliberation was measured through numeracy or manipulated through instructions. The results of Study 3 indicated that few participants are able to calculate correctly the risk numbers necessary to take time into account. Two possible solutions to encourage more purchases of protective measures in the long term are discussed.
\end{abstract}

KEY WORDS: Affect, risk perception, personal experience 


\section{INTRODUCTION}

Recent research has developed and tested theories of judgment and decision making that incorporate affect as a cue in the process of constructing values and preferences. Affect (positive and negative feelings about a stimulus) is thought to substitute for other, less readily accessible information in tasks that require a positive or negative evaluation. ${ }^{(1)}$ Affect can predict and explain a wide variety of judgments and choices ranging from choices among gambles to life satisfaction and valuation of human lives. ${ }^{(2-4)}$ For example, negative affect (often characterized and assessed as anxiety or worry) about health conditions or medical errors appears to facilitate patient interest in adopting protective health behaviors. ${ }^{(5,6)}$ Research has also demonstrated that sunny weather and reading about catastrophes, respectively, can produce positive and negative affective states (i.e., moods) that subsequently alter normatively unrelated evaluations. In particular, stock prices on sunny days were higher than those on less sunny days in cities around the world, ${ }^{(7)}$ and reading a tragic or happy news story produced greater and lesser risk perceptions, respectively, of content-unrelated hazards. ${ }^{(8)}$ "Risk as feelings" is the notion that affect, when present, is thought to act as information and guide risk perceptions; it also guides assessments of value in risky and non-risky decisions (see also the Affect Heuristic ${ }^{(2,9)}$ ). The extent to which affect is used, however, may depend upon whether decisions are considered more immediate (affect matters more) or long term (it matters less), ${ }^{(10)}$ a central issue in the present paper.

This paper examines affect's influence on the purchase of a risk-protective measure. In a previous study, the more positive affect individuals had for a belonging, the more they were willing to pay for insurance and go to the trouble of claiming compensation, holding constant the objective value of the belonging. ${ }^{(11)}$ These results suggest that affect plays a role as information in insurance-related decisions similar to what has been demonstrated in other domains.

Whereas insurance compensates for experienced losses, protective measures such as the deadbolt lock in the current study mitigate the likelihood of future losses. Examples of protective measures include purchasing additional locks to lower the chance of a burglary, removing brush 
and debris from around a home to protect against a potential fire, and installing a car alarm to protect against theft. Given that possible outcomes all occur in the future rather than immediately, it is possible that affect will not matter (although the insurance findings above argue against this possibility). We examine whether a manipulation of time that makes possible outcomes appear more immediate or more distant might alter the extent to which affect is used in judgments.

To begin, we manipulated affect in a manner similar to previous research ${ }^{(11)}$ by describing the extent to which they attributed special meaning to their belongings (i.e., they are affect rich) or had no special feelings about their belongings (i.e., they are affect poor). Even controlling for the costs of belongings, it makes sense to worry more about and invest more in protection for items where you have special feelings (since it presumably would hurt more to lose it compared to something you care about less). Thus, we hypothesized that in purchases of a protective measure (a deadbolt lock):

H1 (Studies 1 and 2): Individuals will demonstrate greater negative affect about losing their belongings and greater intentions to purchase and pay more for a protective measure when belongings are affect-rich than when they are affect-poor.

Affect can function as more than information in judgments and decisions. It also can act as a spotlight drawing attention to some information and away from other information. ${ }^{(12)}$ Strong affect associated with outcomes appears to desensitize people to numeric information such as the probability or magnitude of an outcome. ${ }^{(13,14)}$ Hsee and Rottenstreich $^{(14)}$, for example, demonstrated that strong affect desensitized people to the magnitude or scope of a stimulus in judgments of its subjective value. In their studies, participants, faced with affect-rich objects, appeared to neglect the number of those objects, basing their valuation on the presence or absence of at least one object (e.g., a picture of a cute animal in need of help) while being relatively insensitive to greater numbers of the object (e.g., whether one or four pictured cute 
animals were in need). In contrast, when the object was affect-poor (the same animal depicted with a number of dots), value was closer to a linear function, and decision makers were willing to pay more for larger numbers of the object.

Probability and scope are also important in decisions about protective measures (e.g., the likelihood of a property crime and how much was paid for one's possessions), but, in addition, time can play a critical role. In particular, in purchasing a deadbolt lock or other protective measure, one pays an upfront cost to purchase the item, which then reduces the likelihood and/or consequences of future losses over the length of life of the item. For example, purchasing a dead bolt lock for one's apartment protects the property for as long as the lock is functioning and the property is intact. From a benefit-cost perspective, individuals should be willing to pay more for a protective measure the longer the item provides protection. For example, if the annual chance of a home break-in is $p=.01$, the risk of at least one break-in occurring sometime in the next two years is almost double $(\mathrm{p}=.0199)$; over ten years, the risk of one or more break-ins is $\mathrm{p}=.0956$.

Previous experimental research showed that most individuals do not take into account time and the added benefits of having a protective measure in place over a longer period of time when determining the likelihood of purchasing protection or the maximum they are willing to pay. ${ }^{(15)}$ These studies did not examine the role that affect may play in determining the value of the measure as the length of time that it provided protection was varied. Based on Hsee and Rottenstreich's ${ }^{(14)}$ findings, we reasoned that strong affect might act as a spotlight, drawing attention away from the amount of time that a purchased protective measure was useful and desensitizing participants to time. If one's belongings are affect-poor, on the other hand, we predict that decision makers would be sensitive to how long a purchased protective measure would be useful.

Although Hsee and Rottenstreich ${ }^{(13,14)}$ considered only willingness to pay as their dependent measure, we also examine the likelihood of purchasing a protective measure and the extent to which participants worry about losing their possessions. Based on earlier Affect 
Heuristic results, we expected similar results from each of these variables. This reasoning led us to a time-neglect-with-affect-richness hypothesis:

H2 (Studies 1 and 2): For affect-poor goods, decision makers will report more negative affect (worry) about losing their possessions and greater intentions to purchase and will pay more for a protective measure when living in one's home for a longer compared to a shorter time; more affect-rich belongings, however, will produce time insensitivity.

A balance appears to exist, however, between affect and deliberation. Research demonstrates that changes in the extent of deliberative thought can alter affective influence. For example, decreasing time or capacity for deliberation is thought to increase affective input into risk perceptions. ${ }^{(16)}$. Increasing deliberation may also compromise affective input, even if these deliberations are focused on affective experiences. Lieberman et al. ${ }^{(17)}$ demonstrated that making affective experiences explicit decreased neural activity in the amygdala, a brain area related to emotions. Similarly, increasing deliberation by having participants produce images of an attitude object decreased the association between affect and intended behaviors ${ }^{(18)}$. Finally, Hsee and Rottenstreich $^{(14)}$ demonstrated that increasing deliberation and affect through instructions produced more scope sensitivity and scope neglect, respectively. Thus, affect may play a weaker role when deliberation increases.

If, as described earlier, affect-rich belongings produce time neglect through valuation by feelings, then increased deliberation in that condition should increase sensitivity to time by altering the balance between feelings and deliberation. This paper examines whether increases in deliberation will increase time sensitivity in the affect-rich condition that otherwise would be governed by feelings. We operationalize deliberation in two ways. In Study 1, we examine individual differences in numeracy (or numeric literacy). Past studies have revealed that, whereas highly numerate individuals are more sensitive to and deliberate more about numeric sources of information, the less numerate are more sensitive to non-numeric, often emotional sources of 
information. ${ }^{(19)}$ In Study 2, we manipulate deliberation experimentally through instructions. We test the following hypothesis:

H3 (Studies 1 and 2): Increases in deliberation will produce greater time sensitivity, particularly in the affect-rich condition where valuation is thought to occur through feelings rather than by calculation.

Finally, in Study 2, we consider the role of personal experience (e.g., having your home burglarized) as a possible moderating variable for our hypothesized effects. Research has demonstrated that personal experience has powerful and complex effects on self-protective behaviors. ${ }^{(20)}$ Personal experiences appear to produce more emotional, vivid, concrete, and easier to recall memories, with these emotions acting as direct motivators of behaviors. As a result, we hypothesize that:

H4 (Study 2): Having the personal experience of being burglarized should amplify previously hypothesized effects.

\section{STUDY 1 - AFFECT, TIME NEGLECT, AND NUMERACY}

In Study 1, we provided two sources of numeric information - the time duration of a lease (one or two years) and the small annual likelihood of being burglarized in the event the lock was or was not purchased. These numbers are related, of course, but require some knowledge and calculation to use the numbers properly..$^{(15, \underline{19})}$ Based on the concreteness principle, ${ }^{(21)}$ individuals may not perform these calculations and may instead use the information only in the form in which it was displayed. In the current study, individuals may not realize this relation between time and probability and may be more likely to neglect time as an important variable. This may be less true for highly numerate individuals, however, who are more likely to understand, transform, and use numeric information in decisions. ${ }^{(22-24)}$ For example, more numerate individuals are less susceptible to attribute-framing effects, presumably because they are more likely than the less numerate to transform a given frame (e.g., 26\% incorrect) into the 
normatively-equivalent frame (e.g., 74\% correct) and thus have both frames available at the time of judgment. ${ }^{(23)}$ Consistent with $\mathrm{H} 3$, we expected that greater numeracy would be associated with less time neglect, particularly in the affect-rich condition. Individuals higher in numeracy are expected to deliberate more about the numbers and transform them more often compared to the less numerate and, thus, to integrate the time length of the lease more into their judgments. Presumably because less numerate individuals tend to use non numeric (often emotional) sources of information, they also tend to perceive greater risk from low probability, but consequential risks in the world around them (e.g., $\stackrel{(25-27)}{ })$. As a result, we expected that less numerate individuals would worry more than the highly numerate about being burglarized and would be more likely to purchase and pay more for a protective measure.

\subsection{Methods}

\subsubsection{Participants}

In this study, we used an internet sample maintained at the University of Pennsylvania that varied considerably in its demographics. The final sample $(\mathrm{N}=331)$ was $77 \%$ female with a mean (median) age of 41.6 (41) years (age range=21-80). Education ranged between 10-17 years (where 17 years means anything more than college); the median education was 15 years (equivalent to 3 years of college). Most participants (75\%) had signed a housing lease before.

\subsubsection{Materials}

Participants read the scenario below. For half of the participants, the lease was one-year long, and for the other half of the participants, the lease was two-year long. In addition, half of the participants read the affect-poor scenario, and the other half read the affect-rich scenario; this manipulation replicated that used earlier by Hsee and Kunreuther ${ }^{(11)}$ and was intended to alter feeling-based subjective value.

Suppose you have signed a lease on an apartment in Eugene which commits you to live there for the next year [for the next two years]. The apartment has one 
deadbolt lock, and the landlord is willing to have another one put on the door, but you have to arrange it through the landlord before you move in. You spent about $\$ 3,000$ for the stuff in your apartment.

[ Affect-poor manipulation You don't have any special feelings about the things you bought for your apartment. They are fine for the price and are worth about what you paid for them. A lot of these items are small and could be easily stolen.] [Affect-rich manipulation You love all of the things you bought for your apartment. They are worth a lot more to you than you paid because they have special meaning to you. A lot of these items are small and could be easily stolen.] In order to reduce the chance of theft or burglary, you can pay the landlord to put another dead bolt lock on the door. There is still some chance that your apartment will be burglarized. If this event happens, the cost of replacement of your contents would be $\$ 3,000$. The annual chance of your apartment being burglarized is 2 in 1000. If you purchase the deadbolt lock, the annual chance of your apartment being burglarized is 1 in 1000 . The cost of the deadbolt lock plus installation is $\$ 54$.

Participants were asked about how worried or anxious they would be about being burglarized and losing all of their possessions on a 7-point scale ranging from $0=$ Not at all worried and anxious to $6=$ Extremely worried and anxious. They were asked how likely they would be to buy the dead-bolt lock at a cost of $\$ 54$ on an 11-point verbal scale from $0=$ Certain not to $10=$ Certain as well as on an 11-point numeric scale from $0 \%$ to $100 \%$. The $\$ 54$ cost was provided to limit the range of responses, but this choice produced some problems as noted below. Participants were asked the maximum they would be willing to pay for the deadbolt lock in a free response.

\subsubsection{Numeracy Measure}


A shortened six-item numeracy scale was chosen from a larger set to have a broad range of difficulty. ${ }^{(28)}$ The final scale consisted of 5 items as the 6 th item was not recorded properly. Inferential analyses were conducted using the continuous numeracy score.

\subsection{Results}

Overall, participants were "slightly likely" (mean verbal likelihood=5.9) and 60.6\% certain (mean numeric likelihood) to buy a lock at the stated cost of \$54. Examination of the likelihood variables revealed a relatively flat distribution with a slight negative skew (e.g., the proportions of participants responding Certain not and Certain were 3\% and 11\%, respectively, on the verbal scale. On average, participants were willing to pay (WTP) a maximum of $\$ 61.30$ (median=\$55) for the lock, a surprisingly large amount given that the annual benefit of the deadbolt lock was only $\$ 3$ (i.e., $1 / 1000$ multiplied by $\$ 3,000$ ). This suggests that the expected monetary loss plays a minor role in people's decisions concerning how much to pay for protection. Examination of WTP amounts also revealed a relatively flat distribution (the proportion of respondents with WTPs less than $\$ 15$ and greater than $\$ 100$ were $4 \%$ and 3\%, respectively); however, three popular, focal values existed: $17 \%, 11 \%$, and $18 \%$ of participants, respectively, chose WTP values of $\$ 54$ (the provided cost), $\$ 75$, and $\$ 100$. Average worry was 3.1. Means by condition for each variable can be found in Table I.

The variables also had high intercorrelations $(r=.45$ to $r=.85)$ with the exception of the correlation between Worry and WTP $(r=.29)$. Due to the clumping of WTP responses, we submitted only the remaining three variables - Worry, Verbal Likelihood, and Numeric Likelihood - to a principal components analysis and extracted a single factor explaining $74 \%$ of the variance in responses to represent Lock Intention ${ }^{1}$ (see Dawes ${ }^{(29)}$ ). We then estimated factors scores which, by definition, have a mean of $0(\mathrm{SD}=1)$; factor scores ranged from -2.2 to 1.8 . We dropped WTP responses from further analyses.

To examine the effects of our experimental manipulations and numeracy, a regression model was conducted of the Lock Intention factor scores using time, affect, numeracy, and their 
interaction as independent variables. Means by condition can be found in Table I. The overall model was significant, $\mathrm{F}(7,323)=2.7, \mathrm{p}=.01, \mathrm{R}^{2}=.06$.

As expected from the experiments by Kunreuther, Onculer and Slovic, ${ }^{15}$ Time (whether participants were faced with a 1- or 2-year lease) did not have a significant influence as a main effect $(p=.75)$ Consistent with $\mathrm{H} 1$, participants in the affect-rich condition reported stronger Lock Intentions than those in the affect-poor condition (means $=0.12$ and -0.12 , respectively, $b=.11$, $\mathrm{t}(323)=1.96, \mathrm{p}=.05)$.

Most importantly for H2 (in which we hypothesized time neglect with affect-rich belongings), this main effect was moderated by the interaction of time and affect (time*affect interaction, $\mathrm{b}=-.12, \mathrm{t}(323)=-2.2, \mathrm{p}=.03)$. Participants seemed to show time neglect in their Lock Intention judgments in the affect-rich condition (means in the affect-rich condition were 0.25 and -.02 , respectively, in the one- and two-year conditions, $\mathrm{t}(166)=1.85, \mathrm{p}=.07$ ) but an opposite trend to time sensitivity in the affect-poor condition (means for the 1-year and 2-year lease were -0.22 and -0.03 , respectively, $\mathrm{t}(161)=-1.18, \mathrm{p}=.24)$. Neither of these comparisons were significant, however. See Figure 1a.

Of interest, although the results can be described in terms of time neglect and time sensitivity, other research ${ }^{(10)}$ would suggest that the underlying mechanism for this effect may be the differential use of time in the shorter term versus the longer term. This mechanism would be more in keeping with the functions of affect as information rather than as a spotlight. The data support this mechanism better. In particular, participants appeared to use the information about affect-rich versus affect-poor belongings in the one-year lease condition (means for the affectrich and affect-poor conditions were 0.25 and -0.22 , respectively, $t(165)=-3.02, p=.003)$, but neglected affect in the two-year lease condition (means for the affect-rich and affect-poor conditions were -0.02 and -0.03 , respectively, $\mathrm{t}(162)=-.065, \mathrm{p}=.948)$.

Finally, numeracy is one possible operationalization of an individual difference in deliberation about numbers. From prior literature (e.g.,$\stackrel{(26)}{)}$, we expected that less numerate individuals would worry more about the risk of being burglarized and losing possessions than 
those who were highly numerate and would report being more worried and more likely to purchase a lock (i.e., they would show stronger Lock Intentions). Indeed, this was the case (Lock Intention means $=0.21$ and -0.15 , respectively, for the lowest and highest scorers on numeracy ( cores of 0-2 and 5 correct, respectively, out of 5 possible), $b=-0.11, t(323)=-2.3, p=.02$ ).

We also hypothesized (H3) that individuals higher in numeracy would show greater time sensitivity in the affect-rich condition as they processed and used the numeric information about the length of the lease more than those who were less numerate. H3 was not supported, $b=-.04$, $t(323)=-0.70, p=.48$. No other variables or interactions attained significance.

\subsection{Discussion}

As expected, time (having a one- or two-year lease) did not have a main effect on Lock Intentions in the present study. Similar to what has been demonstrated in retrospective memories

of experience (e.g., $\stackrel{(30)}{)}$, decision makers, on average, appeared to neglect future time when considering its effects on a current decision. The hypothesized effects for affect were generally supported in Study 1. First, the affect-rich manipulation increased Lock Intentions compared to the affect-poor manipulation. These findings are consistent with $\mathrm{H} 1$ and wanting to protect belongings that matter more subjectively to the individual.

Second, for affect-rich items, individuals appeared to show time neglect whereas a nonsignificant time sensitivity was found in the affect-poor condition. That is, individuals were not sensitive to the lease length (1-year vs. 2-years) in wanting to protect belongings for which they had special feelings but were perhaps more sensitive to the lease length in wanting to protect belongings about which they did not have special feelings. These results presumably support separable processes of valuation by calculation (in the affect-poor condition of the present study) and valuation by feeling (in the affect-rich condition). In the latter case, the presence of affect appeared to cause people to use affect as information (pushing up their worry and purchase likelihood). 
At the same time, the results are largely consistent with prior research and theory on the role of affect in shining a spotlight on some information in decisions while causing other information to be neglected. ${ }^{(12)}$ In this case, feeling-based valuation focuses on the possibility that a burglary might happen (at some point in time), and greater feeling (based on affectrichness of belongings) simply increases worry and the likelihood of purchasing the lock. Time appeared to be neglected (in the affect-rich condition only) as an important aspect to weigh in this choice as it was out of the spotlight. Because the risk of at least one burglary accumulates over the time of the lease ( $\mathrm{p}=.01$ for one year and $\mathrm{p}=.0199$ in two years), this neglect of time is a logical error.

The present findings appear more consistent, however, with Loewenstein ${ }^{(10)}$ who suggested that visceral factors, such as affect and emotion or hunger and thirst, may be felt more, and therefore matter more, in the present time than the future. Study 1's results extend this thinking to time periods that are perceived to be closer to the present and reveal that the affect manipulation had a significantly stronger influence in the one-year lease condition that, on average, occurs closer to the present time than the two-year lease condition. Even though the two-year lease length logically includes the first year, our participants nonetheless took into account the "specialness" of their belongings (their affect richness) more when they thought about their home as more temporary. Thus, valuation by feelings is stronger in time periods closer to the present. This difference appears to be the underlying cognitive mechanism explaining the time-neglect findings.

Finally, although less numerate individuals worried more about being burglarized and reported being more likely to purchase a lock (based on their Lock Intention factor scores), numeracy did not influence the extent of time neglect demonstrated (H3 was not supported). Highly numerate individuals are generally more likely to process and use numeric information in decision situations (e.g. $\frac{(23)}{2}$, but numerical thinking did not appear to be activated in this decision. It may be that the higher numeracy scores of the present study were not enough to overcome the difficulties people have in calculating and using cumulative risk (or at least the 
cumulative risk posed in this experiment). Even highly numerate people may not have thought through the fact that the burglary risk increased probabilistically with a longer lease, or they might not have known how to calculate it. We examine this latter possibility in Study 3.

Instead, different non-probabilistic goal states appeared to be elicited in the two timeperiod conditions across all individuals. ${ }^{(31)}$ In particular, when considering a one-year lease, attention was focused on the affect-richness of one's belongings, and this affect was used as information in further evaluations. It is not entirely clear what was the focus of attention in the two-year condition. It may be that a more deliberative mindset was in play, and participants calculated the likelihood of being burglarized and ignored affect. The result "looks like" time neglect with affect richness and an extension of Rottenstreich and Hsee's ${ }^{(13)}$ probability-neglect findings.

Neither of the goal states associated with time frame, however, appeared to elicit mathematical thinking per se (i.e., the calculation of the cumulative two-year risk) since numeracy was unrelated to judgments in all conditions. It may be that decision makers consider time (as indicated by findings in the affect-poor condition) more superficially and intuitively (two years "feels" bigger than one year), without deliberating about the statistical likelihood of being burglarized even in the affect-poor condition. Individuals may need more encouragement to bring their probabilistic abilities to bear on time in this decision. Being more directive about wanting participants to deliberate may encourage more probabilistic processing by individuals. We manipulate deliberation more directly in Study 2. We also examine the alternative hypothesis that individuals lack the ability to make the appropriate calculations needed for the two-year lease condition in Study 3.

\section{STUDY 2 - AFFECT, TIME NEGLECT, DELIBERATION, AND PERSONAL EXPERIENCE}

Study 2 had a similar design to Study 1 with two exceptions. First, half of the participants received a deliberation manipulation explicitly instructing them to think carefully 
about their decision regarding the purchase of the deadbolt lock. Second, at the end of the study, participants indicated whether they had ever been burglarized as a measure of past experience.

We hypothesized (H3) that those who were asked to deliberate about the potential costs and benefits of their decision would be more time sensitive in the affect-rich condition as compared to those who were not asked to deliberate about their decision. Because personal experiences also influence self-protective behaviors by increasing affect, ${ }^{(20)}$ we also examined the hypothesis (H4) that the experience of being burglarized might accentuate Study 1's affect and time-neglect effects.

\subsection{Methods}

\subsubsection{Participants}

Participants $(N=371)$ were recruited through an internet participant pool maintained at Decision Research $($ female $=49 \%$, mean age $=37$, median age $=35)$. Approximately half of the participants (52\%) had at least some college education, and only one individual did not have a high school degree. Eighteen percent of participants $(n=69)$ had been burglarized before and 69\% had signed a lease before.

\subsubsection{Materials}

As in Study 1, the length of lease (1 year vs. 2 years) and affect were manipulated in a between-subject manner. Participants read the following scenario.

Suppose you have signed a lease on an apartment in Eugene which commits you to live there for the next year [the next 2 years]. The apartment has one deadbolt lock, and the landlord is willing to have another one put on the door, but you have to arrange it through the landlord before you move in. You spent about $\$ 3,000$ for the stuff in your apartment.

[(Affect-poor condition) You don't have any special feelings about the things you bought for your apartment. You went to a neighborhood store to select some furniture that you needed. You feel ok with what you bought. Owning these 
pieces of furniture does not particularly reflect any sentimental meaning for you. They are fine for the price and are worth about what you paid for them. A lot of these items are small and could be easily stolen.]

[(Affect-rich condition) You love all of the things you bought for your apartment. You went to stores all around town to carefully select the perfect pieces of furniture to match with the rest of your apartment. You love going home to your apartment, and you feel like owning these pieces of furniture reflect being an adult for the first time. They are worth a lot more to you than you paid because they have special meaning to you. A lot of these items are small and could be easily stolen.]

$[($ Deliberation condition only. $)$ You'd like to make a decision that's right for you. That is, you would like to minimize the money you spend, but at the same time, you want to make a choice that minimizes the risks of your belongings being stolen. Finding the right balance between risks and benefits for you may require some careful thought.]

In making a decision, you'll want to consider the following information. In order to reduce the chance of theft or burglary, you can pay the landlord to put another dead bolt lock on the door. There is still some chance that your apartment will be burglarized. If this event happens, the cost of replacement of your contents would be $\$ 3,000$. The annual chance of your apartment being burglarized is 2 in 1000. If you purchase the deadbolt lock, the annual chance of your apartment being burglarized is 1 in 1000 . The cost of the deadbolt lock plus installation is $\$ 54$. 
Participants were then instructed to answer the verbal likelihood, numeric likelihood, WTP, and worry items asked in Study 1. Finally, they were asked if they had been burglarized before.

\subsection{Results and Discussion}

The distributions of each of the variables were similar to Study 1 (e.g., relatively flat distributions for the likelihood and worry variables and more clumped WTP responses, e.g., 24\% and 14\%, respectively, of participants provided WTP values of $\$ 54$, the provided cost, and \$100). Correlations among the variables were also similar and so we conducted the same principle components analysis of Worry and the two likelihood variables as in Study 1. We extracted a single Lock Intention factor that explained $82 \%$ of the variance in the data, and we again estimated factor scores to represent Lock Intentions (mean=0, $\mathrm{SD}=1$, range=-2.2 to 1.5). A regression analysis was conducted of Lock Intentions with the time manipulation, affect manipulation, deliberation manipulation, burglary experience, and all interactions (except the four-way interaction) as independent variables. All independent variables were mean-centered. See Table II for mean results by affect and the time length of the lease.

On average, participants were "slightly" to "fairly likely" (mean verbal likelihood=6.5) and $62 \%$ certain to buy a lock for $\$ 54$, and they were willing to pay an average of $\$ 54$. Average worry was 3.0.

The overall model was significant, $\mathrm{F}(14,353)=1.7, \mathrm{p}=.05, \mathrm{R}^{2}=.06$. H1 was not supported; individuals in the affect-rich condition did not report increased Lock Intentions compared to those in the affect-poor condition $(\mathrm{p}=.12)$. The experience of being burglarized did matter, with Lock Intentions being higher among those who had been burglarized compared to those who had not (means $=0.19$ and -0.05 , respectively, $\mathrm{b}=-0.16, \mathrm{t}(356)=-2.2, \mathrm{p}=.03$ ). Replicating Study 1 's results and as hypothesized $(\mathrm{H} 2)$, time sensitivity emerged in the affect-poor condition and time neglect in the affect-rich condition, interaction $b=-0.17, t(356)=-2.3, p=.02$. The means in the one- and two-year lease conditions were, respectively, -0.22 and -0.03 in the affect-poor 
condition and 0.15 and 0.14 in the affect-rich condition; see Figure $1 \mathrm{~b}$. In a separate analysis of affect-poor participants, the effect of time was not conventionally significant $(p=.19)$ nor was it in a separate analysis of affect-rich participants only, $p=.93$. Similar to Study 1 , although the results can be described in terms of time neglect and time sensitivity, the underlying mechanism for this effect appears to be the differential use of time in the shorter term versus the longer term ${ }^{(10)}$ In particular, participants appeared to use the information about affect-rich versus affect-poor belongings in the one-year lease condition (means for the affect-rich and affect-poor conditions were 0.15 and -0.22 , respectively, $\mathrm{t}(193)=-2.51, \mathrm{p}=.01$ ), but did not use it significantly in the two-year lease condition (means for the affect-rich and affect-poor conditions were 0.14 and 0.03 , respectively, $\mathrm{t}(174)=-1.19, \mathrm{p}=.24)$.

H3 was not supported; specifically, the deliberation manipulation did not attenuate these time-neglect findings (interaction of deliberation, time, and affect, $\mathrm{p}=.57$ ). Burglary experience, however, tended to accentuate them, as expected (H4), with greater effects of time neglect with affect richness among those who had been burglarized compared to those who had not (threeway interaction $b=.03, t(356)=2.1, p=.04$; see Figure 2). Despite their small sample size $(n=69)$, burglarized participants showed a significant difference between affect conditions in the oneyear lease condition, $\mathrm{t}(33)=-2.27, \mathrm{p}=.03$, but not in the two-year lease condition, $\mathrm{t}(31)=.03$,

$\mathrm{p}=.98$. They did not demonstrate significant time sensitivity in either affect condition. No other effects attained significance with the exception of a non-hypothesized and non-interpretable three-way interaction between the affect and deliberation manipulations and the experience of being burglarized.

\section{STUDY 3 - CALCULATING THE ODDS}

If explicit instructions to deliberate do not alter sensitivity to an important variable such as the length of the lease, one must question whether participants have the requisite knowledge and ability to calculate correctly the likelihood of being burglarized in the two-year lease condition. If decision makers can calculate correctly but tend not to in a decision situation, one 
set of advice is applicable; if they cannot do the calculations correctly, however, different advice should be offered. We turned to this latter simple question in Study 3.

\subsection{Methods}

\subsubsection{Participants}

Participants $(N=174)$ were recruited through the psychology pool at a large Midwestern university (female $=61.5 \%$, mean age $=19.5$, median age $=19)$ and were provided research credit in an introductory psychology course for completion of this study and a set of unrelated studies.

\subsubsection{Procedure}

Participants completed a set of four calculation problems, similar to the problem implicit in the two-year-lease condition of the decision scenarios of Studies 1 and 2. Subsequently, they completed a brief 8-item, psychometrically-valid, numeracy measure. ${ }^{(32)}$

\subsubsection{Materials}

The four calculation questions were as follows:

1. Imagine that, when the Columbus Clippers and the Eugene Emeralds minor league baseball teams have played each other, the Columbus Clippers won only $10 \%$ of the time. If the teams play a double header (two games), by your calculations, what are the chances that the Clippers will win at least once? (Correct answer: 19\%; Approximately correct answers: between 19\% and 20\%)

2. Imagine that, when the Columbus Clippers and the Eugene Emeralds minor league baseball teams have played each other, the Columbus Clippers won only $10 \%$ of the time. If the teams have a four-game series, by your calculations, what are the chances that the Clippers will win at least once? (Correct answer: 34\%; Approximately correct answers: between $34 \%$ and $40 \%$ )

3. Imagine that, while driving in Columbus, you always tend to speed 5-10 miles per hour over the speed limit, and you estimate that you have a $1 \%$ chance of getting a 
speeding ticket sometime in the next year. If you continue driving like this, by your calculations, how likely are you to get at least one speeding ticket in the next TWO years? (Correct answer: $1.99 \%^{2}$ or $2 \%$; Approximately correct answer: $2 \%$ )

4. Imagine that, while driving in Columbus, you always tend to speed 5-10 miles per hour over the speed limit, and you estimate that you have a $1 \%$ chance of getting a speeding ticket sometime in the next year. If you continue driving like this, by your calculations, how likely are you to get at least one speeding ticket in the next THREE years? (Correct answer: $2.97 \%^{3}$ or $3 \%$; Approximately correct answer: $3 \%$ )

\subsection{Results and Discussion}

The average numeracy score was $4.2(\mathrm{SD}=1.7)$ out of 8 possible. The calculation questions were scored as correct if participants gave the exact answer (rounded to the nearest whole percentage). Participants did not score well on the calculation questions. On each of the questions 1-4 above, respectively, $2.3 \%, 1.2 \%, 57.0 \%$, and $54.0 \%$ of the participants answered the problem correctly. A count variable was computed as the number of times an individual responded correctly across the four items. The average number of correct responses was 1.15 $(\mathrm{SD}=0.97$, range $=0-3)$. Over a third of the sample did not answer any of the questions correctly (39\%); an additional $8 \%, 52 \%, 1 \%$ and $0 \%$, respectively, responded to $1,2,3$, and all 4 questions correctly. Of some surprise to us, the correlation between numeracy and the number of correct items was not significant $(\mathrm{r}=.11, \mathrm{p}=.14)$.

We examined common mistakes. Participants' most common mistake was an insensitivity to the difference between the chance of occurrence given a single event versus its chance given multiple events. For example, the probability of the Columbus Clippers winning one game in one attempt was given as $10 \%$, but, when faced with two or three games (instead of the one game), participants did not update the likelihood of winning accordingly. Said another way, a large proportion of participants believed that a $10 \%$ chance of winning at least one game was always $10 \%$, regardless of how many games were played. In questions 1-4, respectively, 
$33.3 \%, 24.3 \%, 20.8 \%$, and $16.9 \%$ made this common error. The correlation between the number of times a participant made this first common mistake and numeracy was $r=-0.04, p=.59$. In other words, highly numerate participants did not avoid this error.

Another common mistake was to simply multiply the given percentage by the number of years (e.g., if there is a $10 \%$ chance in one game, then there should be a $40 \%$ chance in four games). For questions 1 and 2, respectively, $24.1 \%$ and $17.9 \%$ of participants made this mistake. Note that use of this strategy would produce errors in questions 1 and 2, but would produce what we coded as the correct response in questions 3 and 4 (because we coded responses as correct if they might have been rounded to the nearest whole percentage). It seems likely that use of this strategy is one of the primary reasons for the greater proportion of correct responses for questions 3 and 4 . The correlation between the number of times a participant made this second common mistake and numeracy was $r=0.03, p=.66$. We should note that, although both of these strategies produce incorrect answers, the former represents an insensitivity to the context of time when considering risk, whereas the latter represents a sensitivity to time but an inability or unwillingness to perform the appropriate calculations.

We can also calculate the number of approximately correct answers if we allow this latter mistake to be close enough for the decision situations of Studies 1 and 2. We combine these responses with actual correct responses. In each of the questions 1-4 above, respectively, 26\%, $20 \%, 57 \%$, and $54 \%$ of the participants answered the problem at least approximately correctly. A second count variable was computed of the number of correct plus approximately correct responses. The average number of at least approximately correct responses was $1.57(\mathrm{SD}=1.29$, range $=0-4$ ). Almost a third of the sample still did not answer any of the questions approximately correctly (30.5\%); an additional $12 \%, 37 \%, 10 \%$ and $10 \%$, respectively, responded to $1,2,3$, or all 4 questions approximately correctly. Again of surprise to us, the correlation between numeracy and the number of at least approximately correct items remained quite low $(\mathrm{r}=.08$, $\mathrm{p}=.29)$. 
One other possibility is that decision makers may have the intuition that the likelihood of being burglarized is higher in the two-year than the one-year condition even if they cannot calculate the correct response. If true, this could potentially explain the small effect of time in the affect-poor condition. Thus, we calculated the number of responses that were greater than the base rate given. For example, in question 1 , the given base rate was $10 \%$; responses greater than $10 \%$ were counted as "intuitively higher;" responses of $10 \%$ or less were not. The same procedure was followed for each of the four questions. In each question 1-4 above, respectively, $44 \%, 44 \%, 91 \%$, and $84 \%$ of the participants answered the problem with a number greater than the base rate. A count variable was computed of the number of intuitively higher responses. The average number of intuitively higher responses was $2.64(\mathrm{SD}=1.09$, range $=0-4)$. Only $5 \%$ of the sample still did not answer any of the questions as higher than the provided base rate; an additional $4 \%, 40 \%, 23 \%$ and $28 \%$, respectively, responded to $1,2,3$, or all 4 questions approximately correctly. The correlation between numeracy and the number of intuitively higher items was quite low $(\mathrm{r}=.01, \mathrm{p}=.86)$.

We conclude that this kind of numeric problem poses particular difficulty for individuals lower and higher in numeracy even when asked directly to respond and even among the relatively numerate college-educated sample of the present study. Given that we did not request any explicit calculations in the decision scenarios of Studies 1 and 2, it seems likely that an even lower proportion of the population would have calculated the odds of being burglarized at least once when given the two-year lease condition.

The results underscore recommendations made in the health literature that decision makers should not be asked to make inferences or calculations in the course of decisions (e.g., ${ }^{(33-}$ ${ }^{35)}$ ). Instead, information providers should do the math for them. In the case of the decision in Studies 1 and 2, the risk should not be provided as an annual chance (1\%), but, instead, should be provided as the chance of being burglarized at least once for the full time period of interest $(1.99 \%$ or $2 \%)$. 


\section{GENERAL DISCUSSION}

\subsection{Summary of Affect Results and Implications for Affect Theory}

The present results contribute further to knowledge about the importance of affect, deliberation, and individual differences to behavior related to managing risks. Decision makers appeared to use affect as information in a heuristic fashion. ${ }^{(2)}$ Support for affect as information comes from findings that Lock Intentions (the common variance shared by the verbal and numeric measures of the likelihood of buying a lock and the measure of worry about being burglarized and losing one's possessions) tended to be generally higher in the affect-rich condition compared to the affect-poor condition. This finding is consistent with wanting to protect items that are more special. However, the finding that affect has a greater effect in the shorter term condition does not make logical sense, particularly given that the two-year term condition contains the one-year short-term lease. The finding is perfectly consistent, however, with previous psychological research demonstrating that visceral factors such as affect matter more in time periods closer to the present. $\frac{(10)}{}$

Alternatively, the findings could be interpreted as providing support for affect acting as a spotlight. We found in Studies 1 and 2 that participants demonstrated (nonsignificant) greater sensitivity to time in their Lock Intentions when their belongings were described as affect-poor; they largely showed time neglect with belongings described as special and affect-rich. Given the consistent significance of the affect manipulation in the one-year lease condition and its nonsignificance in the two-year lease condition, however, the interaction (and apparent time neglect with affect richness) appears to be better explained through a modified view of the Affect Heuristic $^{(2)}$ in that affect's role in guiding risk perceptions may be primarily true when consequences appear close to the present time and not in the distant future. The different use of affect likely also explains the apparent reversal in evaluations in the affect-rich conditions from the one-year to the two-year lease condition (i.e., Lock Intentions were somewhat lower in the two- than the one-year lease condition in Studies 1 and 2). 
When evaluating possible protection of belongings in the one-year lease condition, decision makers appear to weigh the specialness of affect-rich versus affect-poor belongings. Affect did not appear to influence judgments when faced with the two-year lease condition. This interaction effect was modest but robust. It is not clear in either lease condition whether participants took into account the annual chance of burglary since we did not directly manipulate this likelihood. It seems likely, however, that a sizeable proportion of our participants (including those who were highly numerate) did not understand the logical link between the likelihood of a burglary and the amount of time for the lease. This speculation is supported by the results of Study 3 in which participants were quite poor at responding correctly to similar problems posed as math questions.

However, a trend existed in both Studies 1 and 2 suggesting that affect-poor participants, may, in fact, use time to some extent. Specifically, Lock Intention means were higher among them for the two- than the one-year lease condition (although the means in neither study were significantly different, this replication may indicate an important finding that future research should explore). These results may be due to the small proportion of individuals who can calculate an at least approximately correct likelihood in the two-year lease condition, or they could be due to the heuristic use of time in some fashion (e.g., about half of Study 3's participants provided responses that were greater than the base rate on 3 or 4 of the 4 problems posed). Extending the time of the lease out further or highlighting the time length of the lease more may amplify these results (in Studies 1 and 2, the lease length was mentioned only briefly at the beginning of the scenario). It is not entirely clear at this point what information participants used in the two-year condition. We do know that valuation by feeling (as indexed by reactions to affect-rich compared to affect-poor belongings) was stronger in time periods closer to the present, amplifying our time-neglect results.

Study 2 results suggested, however, that the affect manipulation also had stronger effects among participants with previous related experience. Individuals who had previously been burglarized likely had more emotional, vivid, concrete, and easier to recall memories of the 
burglary and the belongings they lost ${ }^{(20)}$, and the affect manipulation may have further increased memory accessibility and amplified the hypothesized effects. Thus, the effects theorized by Loewenstein (at least for this context) appeared to have two boundary conditions: One, the judgment or decision being made has to have short term consequences (the effect is not limited to the immediate time only), and experience is required in order for the effect to occur. Practically speaking, this suggests that having decision makers think about what they would do as if consequences were in the future (even if the decision really does have immediate consequences) could be of some benefit if it was thought that they were overweighing some affect-rich portion of the decision situation.

It may be that the experience of being burglarized elicited a stronger goal to protect belongings compared to not-burglarized participants. This goal state then may have contributed to burglarized individuals weighing the time of the lease more in the affect-poor condition. In fact, previously-burglarized people worried more about being burglarized and were more likely to buy a second lock than those who had never been burglarized before, particularly in the twoyear lease condition. Consistent with Loewenstein's ${ }^{(10)}$ visceral influences paper, the affect-rich manipulation also had a particularly strong effect on them in the one-year lease condition. Personal experience may not change the nature of the underlying psychological processes that influence how we value protective measures (i.e., experienced individuals used affect as information), but it appears to change the strength with which those mechanisms exert themselves.

Personal experience also may play a moderating role in other experiments that vary the affect richness of stimuli. Its role may be especially important among participants who have had more life experience than the university students who more commonly act as participants in experimental studies, however. Studies 1 and 2 in the present paper were conducted with nonuniversity samples; we suspect that our results would have been greatly attenuated if we had tested a university sample that had less life experience, including the experience of being burglarized. 


\subsection{The Role of Deliberation and Calculation in Risk Perceptions}

Valuation by deliberation is thought to occur in the affect-poor condition; in fact, we see some greater sensitivity to time when the belongings were described as affect poor. However, we also expected (H3) that greater deliberation would attenuate time neglect in affect-rich conditions; this hypothesis did not receive support across Studies 1 and 2. In Study 1, although greater numeracy was associated with lower Lock Intentions, numeracy was not significantly associated with time neglect, suggesting that this type of decision situation (at least as portrayed in the present studies) did not elicit probabilistic thinking. In Study 2, the deliberation instructions did not have any significant effects (with the exception of the one non-hypothesized and non-interpretable three-way interaction). Additional research on instructions that might encourage more logical, probabilistic thinking is needed.

Study 3's results also suggested that decision makers need additional assistance. In particular, the results of Study 3 demonstrated that individuals are quite poor at the kinds of calculations implicit to the decision situation of Studies 1 and 2. Thinking harder will not help in such situations where decision makers lack the requisite numeric ability. We conclude that risks (and benefits) should not be provided in ways that require any kind of calculation or inference from the decision maker, but instead, any important number should be treated as important and should be calculated for the decision maker. ${ }^{(33-35)}$ Note that the choice of the precision with which to provide the information may be another important feature. Witteman et al., ${ }^{(36)}$ for example, demonstrated that patients trust risk numbers less when more significant digits are shown after the decimal (e.g., 1.99\% may be trusted less than $2 \%$ ).

\subsection{Final Thoughts}

The findings on time neglect suggest the need to develop strategies to encourage individuals to invest in protective measures where upfront costs exist but where the benefits extend over time, as in the case of dead bolt locks. For example, risk-reducing measures on residences in hazard-prone areas (e.g., installing shutters on property in hurricane prone areas) are generally not adopted because individuals do not appreciate the long-term benefits of these 
measures. The present results even point towards the possibility that home owners may be less likely to adopt these measures if they care a lot about their belongings and plan to live in their home for a long time compared to a short period. Participants may be more sensitive to time if cumulative risk is calculated and presented to them; this remains an empirical question.

A different possible solution to this time-neglect dilemma is to spread the cost of the investment over time through long-term loans coupled with multi-year insurance policies tied to the property, thereby making these protective measures financially attractive. More specifically, for purchases of cost-effective measures, the annual premium reduction from reducing the risk is likely to be greater than the yearly loan payment. Long-term contracts such as these have recently been proposed for modifying the National Flood Insurance Program. ${ }^{(37)}$ More empirical research is needed to determine whether these proposals will be attractive to individuals subject to low probability-high consequence events, such as burglaries or natural disasters, where opportunities exist to invest in protection today to reduce the risks of large scale losses in the future. 


\section{REFERENCES}

1. Kahneman D. A perspective on judgment and choice: Mapping bounded rationality. American Psychologist, 2003; 58(9):697-720.

2. Slovic P, Finucane ML, Peters E, MacGregor DG. The affect heuristic. In Gilovich T, Griffin D, Kahneman D, editors. Heuristics and biases: The psychology of intuitive judgment. New York: Cambridge University Press; 2002. p. 397-420.

3. Kahneman D, Schkade D, Sunstein, CR. Shared outrage and erratic awards: The psychology of punitive damages. Journal of Risk and Uncertainty, 1998; 16:49-86.

4. Schwarz N, Clore, GL. Mood, misattribution, and judgments of well-being: Information and directive functions of affective states. Journal of Personality and Social Psychology, $1983 ; 45: 513-23$.

5. Diefenbach MA, Miller SM, Daly M. Specific worry about breast cancer predicts mammography use in women at risk for breast and ovarian cancer. Health Psychology, 1999; 18:532-36.

6. Peters E, Slovic P, Hibbard JH, Tusler M. Why worry? Worry, risk perceptions, and willingness to act to reduce medical errors. Health Psychology, 2006; 25:144-152.

7. Hirshleifer D, Shumway T. Good day sunshine: Stock returns and the weather. The Journal of Finance, 2003; 58:1009-32.

8. Johnson EJ, Tversky A. Affect, generalization, and the perception of risk. Journal of Personality and Social Psychology, 1983; 45:20-31.

9. Loewenstein GF, Weber EU, Hsee CK, Welch ES. Risk as feelings. Psychological Bulletin, 2001; 127(2):267-86. 
10. Loewenstein G. Out of control: Visceral influences on behavior. Organizational Behavior and Human Decision Processes, 1996; 65:272-92.

11. Hsee C, Kunreuther H. The affection effect in insurance decisions. Journal of Risk and Uncertainty, 2000; 20:141-59.

12. Peters E. The functions of affect in the construction of preferences. In Lichtenstein S, Slovic P, editors. The construction of preference. New York: Cambridge University Press; 2006. p. $454-63$.

13. Rottenstreich Y, Hsee CK. Money, kisses, and electric shocks: On the affective psychology of risk. Psychological Science, 2001; 12(3):185-90.

14. Hsee CK, Rottenstreich Y. Music, pandas, and muggers: on the affective psychology of value. Journal of Experimental Psychology: General, 2004; 133:23-30.

15. Kunreuther H, Onculer A, Slovic P. Time insensitivity for protective investments. Journal of Risk and Uncertainty, 1998; 16: 279-299.

16. Finucane ML, Alhakami A, Slovic, P, Johnson, SM. The affect heuristic in judgments of risks and benefits. Journal of Behavioral Decision Making, 2000; 13:1-17.

17. Lieberman MD, Eisenberger NI, Crockett MJ, Tom SM, Pfeifer JH, Way BM. Putting feelings into words. Psychological Science, 2007; 18(5):421-428.

18. Peters E, Slovic P. Affective asynchrony and the measurement of the affective attitude component. Cognition and Emotion, 2007; 21(2):300-329.

19. Peters E. Beyond comprehension: The role of numeracy in judgments and decisions. Current Directions in Psychological Science, in press.

20. Weinstein ND. Optimistic biases about personal risks. Science, 1989; 246:1232-33. 
21. Slovic P. From Shakespeare to Simon: Speculations-and Some Evidence-About Man's

Ability to Process Information. Oregon Research Institute Research Bulletin, 1972; 12(2).

22. Keller C, Siegrist M. Effect of risk communication formats on risk perception depending on numeracy. Medical Decision Making, 2009; 29:483-90.

23. Peters E, Västfjäll D, Slovic P, Mertz CK, Mazzocco K, Dickert S. Numeracy and decision making. Psychological Science, 2006; 17(5):408-14.

24. Peters E, Levin IP. Dissecting the risky-choice framing effect: Numeracy as an individualdifference factor in weighting risky and riskless options. Judgment and Decision Making, $2008 ; 3: 435-48$.

25. Woloshin S, Schwartz LM, Black WC, Welch HG. Women's perceptions of breast cancer risk: How you ask matters. Medical Decision Making, 1999; 19:221-9.

26. Dieckmann NF, Slovic P, Peters EM. The use of narrative evidence and explicit probability by decision makers varying in numeracy. Risk Analysis, 2009; 29:1473-88.

27. Lipkus IM, Peters E, Kimmick G, Liotcheva V, Marcom P. Breast cancer patients' treatment expectations after exposure to the decision aid program, Adjuvant Online: The influence of numeracy. Medical Decision Making, 2010: 30:464-73.

28. Peters E, Dieckmann N, Dixon A, Hibbard JH, Mertz CK. Less is more in presenting quality information to consumers. Medical Care Research \& Review, 2007; 64:169-90.

29. Dawes RM. Suppose we measured height rating with scales instead of rulers. Applied Psychological Measurement, 1977; 1(2):267-273. 
30. Fredrickson BL, Kahneman D. Duration neglect in retrospective evaluations of affective episodes. Journal of Personality and Social Psychology, 1993; 65:45-55.

31. Krantz DH, Kunreuther HC. Goals and plans in decision making. Judgment and Decision Making, 2007; 2:137-68.

32. Weller J, Dieckmann NF, Tusler M, Mertz CK, Burns W, Peters E. Development and testing of an abbreviated numeracy scale: A Rasch Analysis approach. In review.

33. Peters E, Hibbard J, Slovic P, Dieckmann N. Numeracy skill and the communication, comprehension, and use of risk-benefit information. Health Affairs, 2007; 26(3):741-748.

34. Lipkus IM. Numeric, verbal, and visual formats of conveying health risks: Suggested best practices. Medical Decision Making, 2007; 27:696-713.

35. Fagerlin A, Ubel PA, Smith DM, Zikmund-Fisher BJ. Making numbers matter: Present and future research in risk communication. American Journal of Health Behavior, 2007; 31(Suppl 1), S47-S56.

36. Witteman HO, Zikmund-Fisher BJ, Water EA, Gavaruzzi T, Fagerlin A. Risk estimates from $\underline{\text { an online risk calculator are more believable and recalled better when expressed as }}$ integers. Journal of Medical Internet Research, 2011; 13(3):e54), doi:10.2196/jmir.1656

37. Kunreuther HC, Michel-Kerjan EO. From market to government failure in insuring U.S. natural catastrophes: How can long-term contracts help. In Brown J, editor. Private markets and public insurance programs. Washington, D.C: American Enterprise Institute Press; 2010. 


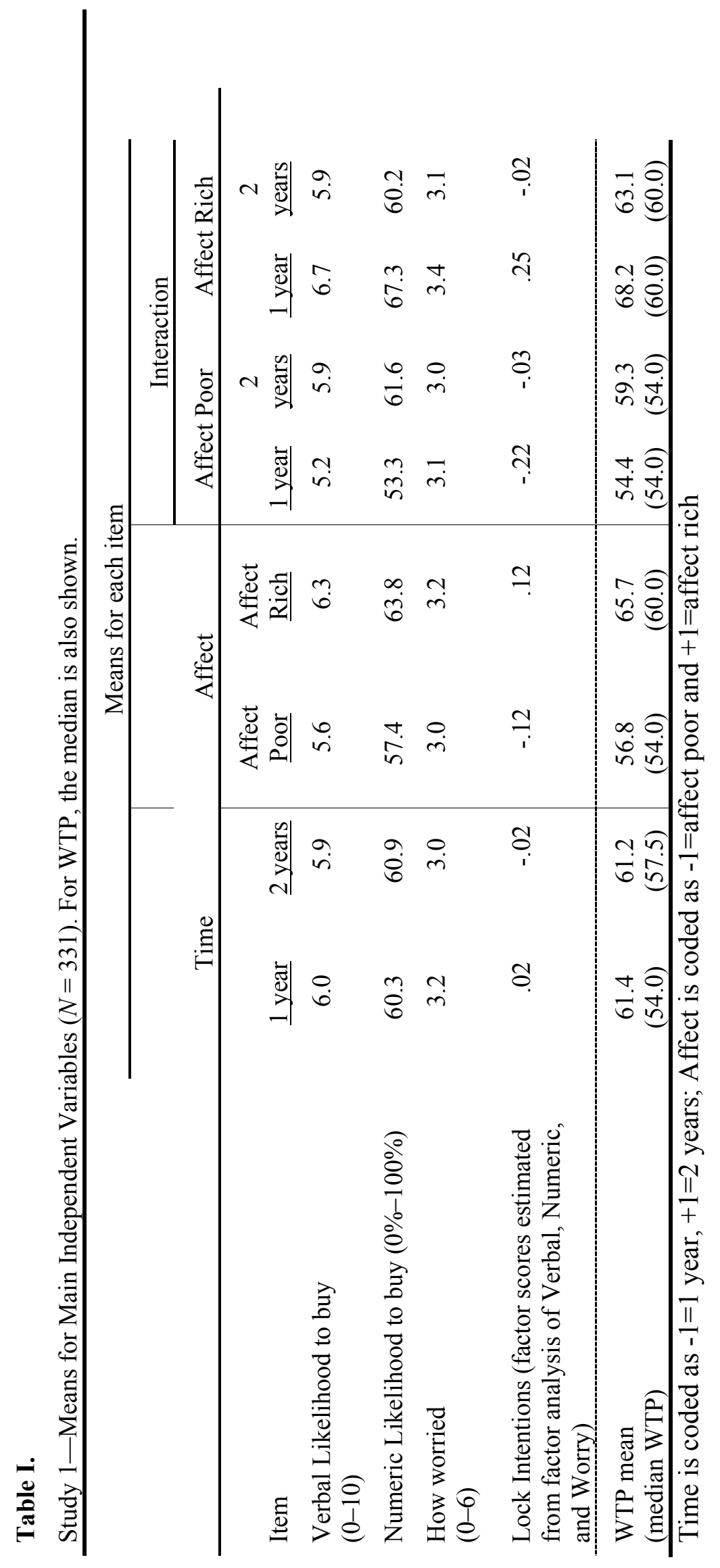




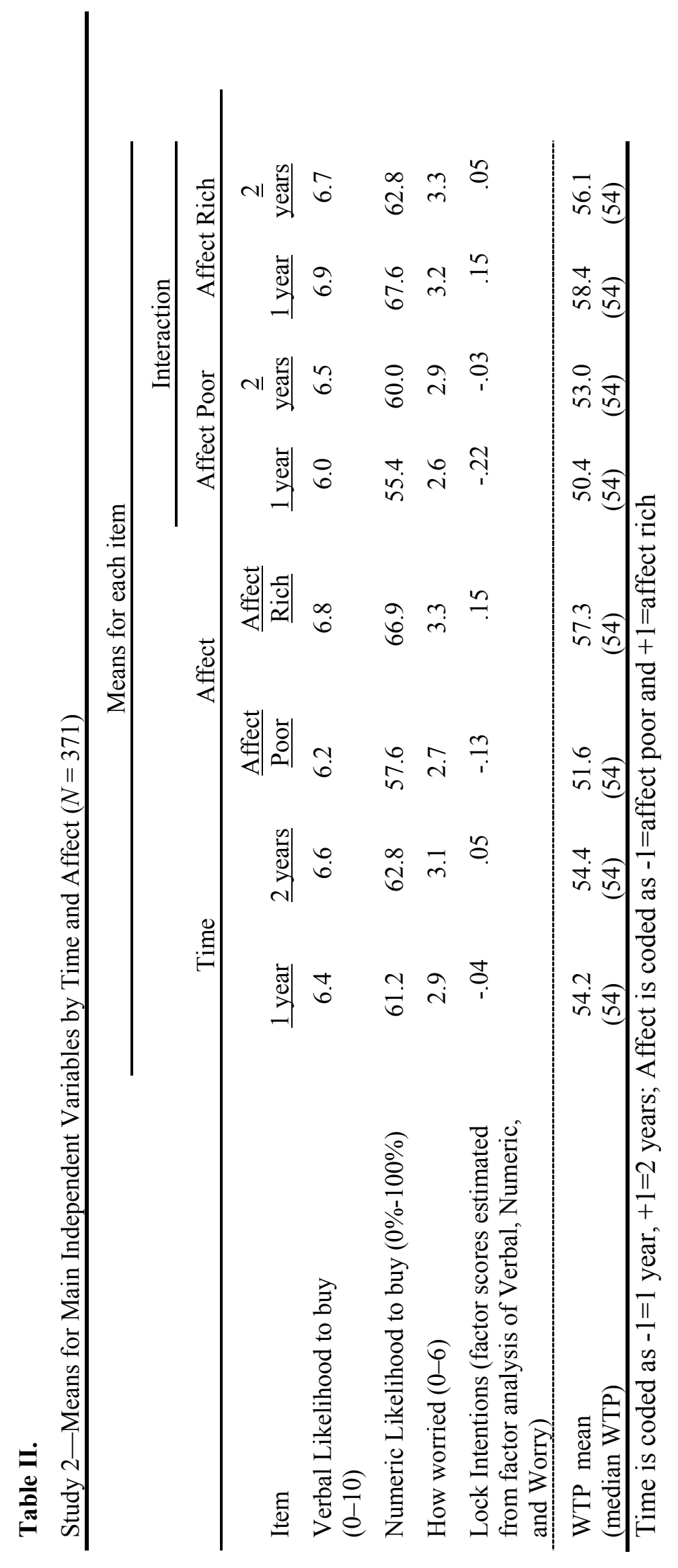




\section{Figure 1.}

Studies 1 and 2 - Lock Intention factor score means for the two-way interaction between time and affect (+/- one standard error bars are shown).

a) Study 1

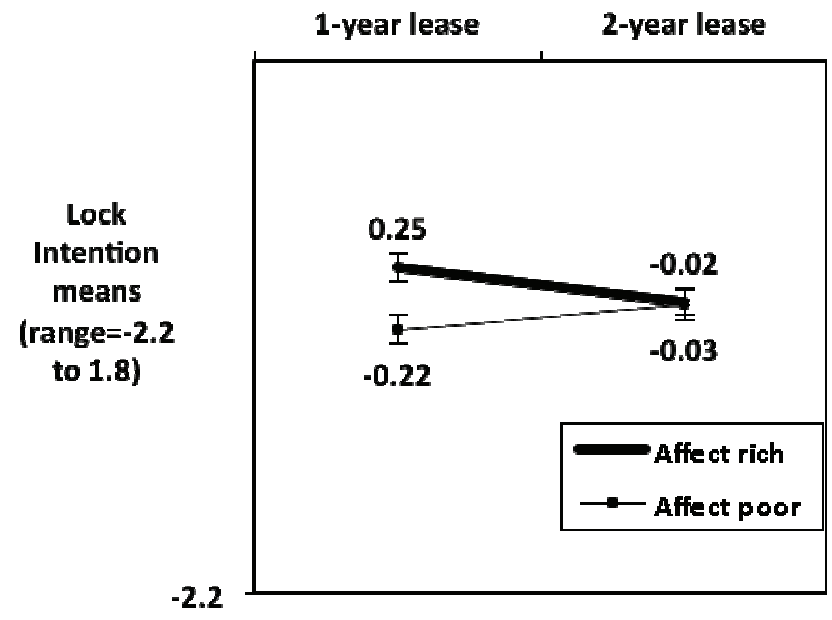

b) Study 2

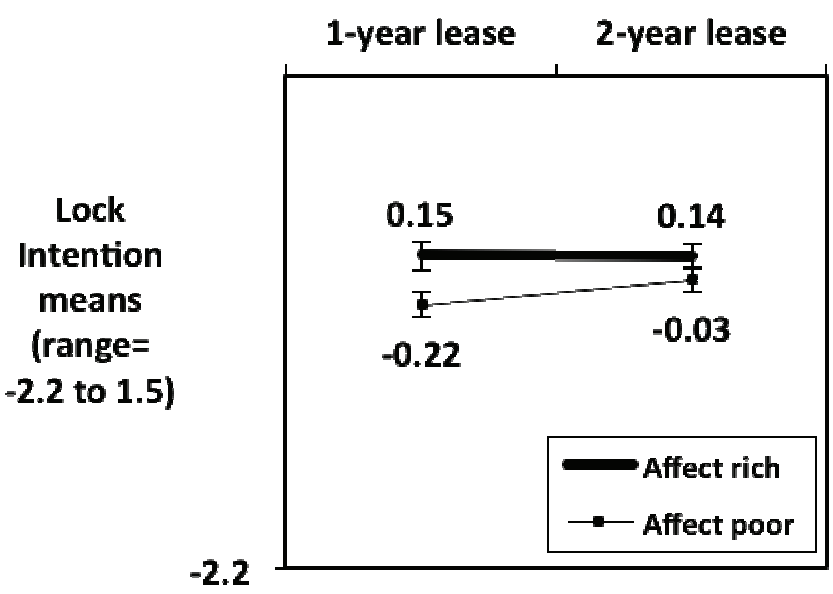




\section{Figure 2.}

Study 2 - Lock Intention means for the three-way interaction between time, affect, and burglary experience (+/- one standard error bars are shown).
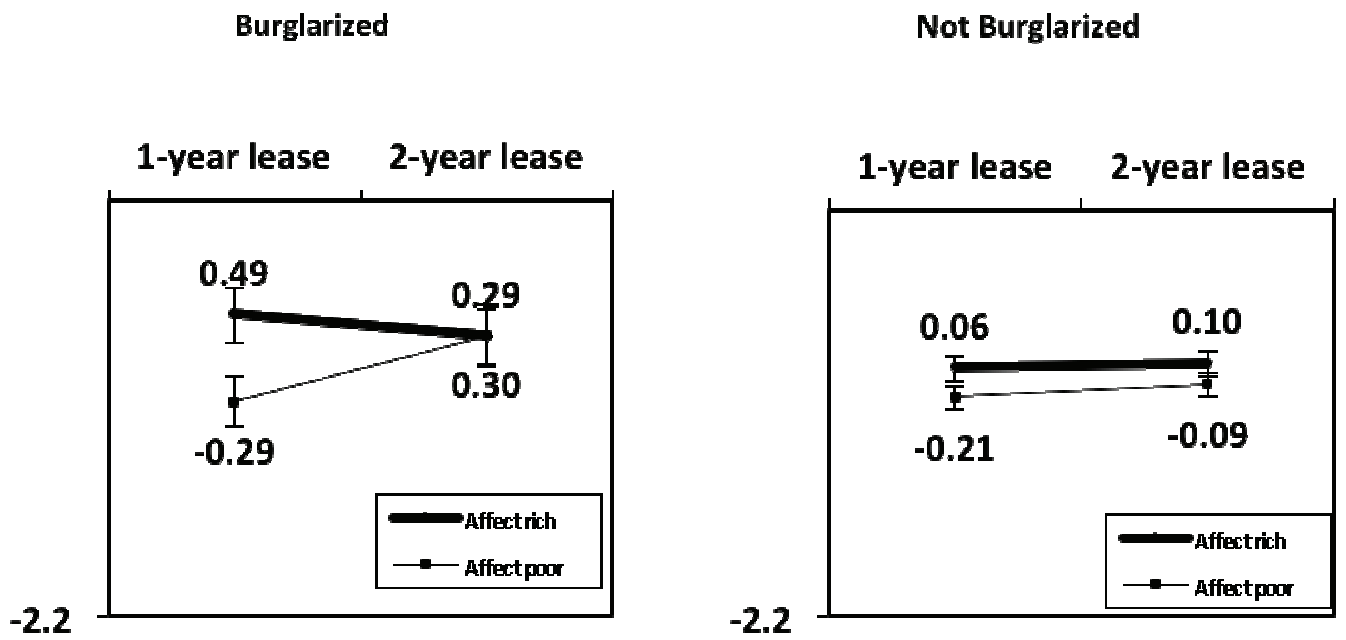


\section{Footnotes.}

${ }^{1}$ A factor analysis using only numeric and verbal likelihoods produced similar results in factoranalytic and experimental result. We include all three variables as a richer conceptualization of Lock Intentions that highlights the important role of affect (i.e., risk as feelings) in risk perceptions.

${ }^{2}$ Only one person $(0.5 \%$ of the sample) gave the actual correct answer of $1.99 \%$.

${ }^{3}$ Only one person $(0.5 \%$ of the sample) gave the actual correct answer of $2.97 \%$. 